\title{
Neurocomputational modeling of imitation deficits
} Biljana Petreska* and Aude G Billard

\author{
Address: Learning Algorithms and Systems Laboratory (LASA), Ecole Polytechnique Fédérale de Lausanne (EPFL), CH-1015 Lausanne, Switzerland \\ Email: Biljana Petreska* - biljana.petreska@epfl.a3.ch \\ * Corresponding author
}

from Seventeenth Annual Computational Neuroscience Meeting: CNS*2008

Portland, OR, USA. 19-24 July 2008

Published: II July 2008

BMC Neuroscience 2008, 9(Suppl I):P76 doi: I0.1 I86/I47I-2202-9-SI-P76

This abstract is available from: http://www.biomedcentral.com/I47I-2202/9/SI/P76

(C) 2008 Petreska and Billard; licensee BioMed Central Ltd.

\section{Introduction}

We are interested in the question of human imitation and we address this through convergent evidence from neuroscience. The rationale of our work is that the nature of imitation deficits following brain lesion can unveil some of the neural and computational principles underlying normal imitation. In particular, we consider how imitation of meaningless gestures (i.e., hand postures relative to the head) is impaired in apraxia [1], i.e., an inability to perform voluntary movements that cannot be explained by elementary motor, sensory or cognitive deficits.

We have first considered a clinical study of visuo-motor imitation of meaningless gestures in an apraxic patient with damage to the corpus callosum [2]. Interestingly the patient made different errors depending on the visual field of presentation of the stimulus and the hand used, with preserved imitation only in the right visual field right hand condition. These observations brought us to consider modeling of the information pathway across the two hemispheres and the type of connectivity impairment which would account for them. We have thus developed a leaky integrator neurocomputational model of the neural representations of different sensory information (e.g., visual, tactile or proprioceptive) and reciprocal nonlinear transformations necessary to perform the imitation task [3]. The sensory representations in our model are selforganizing maps whose interconnections are trained with anti-hebbian learning. The information flow and implementation details of the model are consistent with evidence from brain imaging and neurophysiological studies $[4,5]$. To simulate callosal apraxia, we added uncertainty in the transfer of information between sensory representa- tions localized in different hemispheres, successfully reproducing the results found in [3].

To summarize, our model makes hypotheses on the type of neural representations used and the computational mechanisms underlying human visuo-motor imitation and could possibly help to gain more understanding in the occurrence and nature of imitation errors in patients with brain lesions. In addition, to further test and validate the model against human motion experimental data, we conduct, in collaboration with the Geneva University Hospital (HUG) and Vaud University Hospital Center (CHUV), kinematic studies with brain damaged adults specifically disabled in gesture imitation.

\section{Acknowledgements}

This work has been supported by the Sport and Rehabilitation Engineering Program EPFL.

\section{References}

I. Petreska B, Adriani M, Blanke O, Billard AG: Apraxia. A review. From Action to Cognition. Progress in Brain Research 2007, 164:6I-83.

2. Goldenberg G, Laimgruber K, Hermsdörfer J: Imitation of gestures by disconnected hemispheres. Neuropsychologia 200I, 39:1432-1443.

3. Petreska B, Billard AG: A neurocomputational model of an imitation deficit following brain lesion. Proceedings of I 6 th International Conference on Artificial Neural Networks (ICANNO6) LNCS 2006, 4I3 I:770-779.

4. Decety J, Grèzes J, Costes N, Perani D, Procyk E, Grassi F, Jeannerod $M$, Fazio $F$ : Brain activity during observation of actions: influence of action content and subject's strategy. Brain 1997, I 20:1763-1777.

5. Mühlau M, Hermsdörfer J, Goldenberg G, Wohlschläger AM, Castrop F, Stahl R, Röttinger M, Erhard P, Haslinger B, Ceballos-Baumanna $A O$, et al.: Left inferior parietal dominance in gesture imitation: an fMRI study. Neuropsychologia 2005, 43: 1086-98. 